DEBATES 



\section{O SAGRADO NA VIDA COTIDIANA ${ }^{1}$}

Michel Leiris

O que é, para mim, o sagrado? Mais exatamente: em que consiste o meu sagrado? Quais são os objetos, os lugares, as circunstâncias que despertam em mim esse misto de temor e de apego, essa atitude ambígua determinada pela aproximação de algo ao mesmo tempo atraente e perigoso, prestigioso e rejeitado, esta mistura de respeito, de desejo e de terror que pode passar pelo sinal psicológico do sagrado?

Não se trata aqui de definir minha escala de valores - na qual o que há para mim de mais grave e sagrado, no sentido comum do termo, ocuparia o topo. Antes, trata-se de buscar em alguns fatos bem simples, colhidos na vida cotidiana e situados fora do âmbito do que constitui atualmente o sagrado oficial (religião, pátria, moral), de desvendar, através dos mínimos fatos, quais os traços que permitiriam caracterizar qualitativamente o meu sagrado e ajudar a fixar o limite a partir do qual eu sei que não me movimento mais no plano das coisas ordinárias (fúteis ou sérias, agradáveis ou dolorosas), mas que penetrei num mundo radicalmente distinto, tão diferente do mundo profano como são diferentes o fogo e a água.

Parece evidente que tudo o que nos fascinou durante a infância e nos deixou a lembrança de uma perturbação semelhante deve ser questionado em primeiro lugar. De fato, de todos os materiais de que podemos dispor, os que são extraídos das brumas da infância parecem representar os menos sofisticados.

Reportando-me mentalmente à minha infância, encontro em primeiro lugar alguns ídolos, alguns templos e, de uma maneira mais geral, alguns lugares sagrados.

1 Tradução de Adelia Yates sob a supervisão de Patrícia Reuillard (UFRGS). Revisão técnica de Emerson Giumbelli (UFRGS) e Júlia Goyatá (USP). 
Em primeiro lugar, alguns objetos pertencentes a meu pai, símbolos de sua força e de sua autoridade. Seu chapéu alto de abas retas, que à noite ele pendurava no cabide, ao chegar do escritório. Seu revólver, um Smith \& Wesson de tambor, perigoso, como todas as armas de fogo, e ao mesmo tempo tão atraente por ser de metal niquelado, instrumento que ele costumava guardar na gaveta de uma escrivaninha ou na mesa de cabeceira e que era o atributo por excelência de quem estava incumbido, entre outras tarefas, de manter a casa e protegê-la dos ladróes. Sua niqueleira, onde guardava luíses, mistura de cofre forte e joia, que durante muito tempo foi privilégio exclusivo do mantenedor da casa e que nos parecia, a meus irmáos e a mim, até o momento em que ganhamos uma parecida como presente de primeira comunhão, a marca da idade viril.

Outro ídolo era a salamandra, a "Radiosa", adornada com uma efígie de mulher que se assemelhava a um busto da República. Verdadeiro gênio do lar, reinava na sala de jantar. Atraente pelo calor que espalhava, pela incandescência de seus carvões; temida porque meus irmãos e eu sabíamos que, se a tocássemos, nos queimaríamos. Era para perto dela que me levavam à noite, quando acordava tomado por acessos de tosse nervosa que caracterizavam o "falso-crupe" e quando, atacado por um mal sobrenatural noturno e devastado pela tosse que se introduzia em mim como um corpo estranho, eu tinha a sensação de que me tornava, de repente, alguém de muito prestígio - como o herói de uma tragédia -, estando cercado pela inquietação e solicitude afetuosa de meus pais.

Quanto aos lugares, há primeiramente o quarto parental, que só adquiria seu sentido pleno durante a noite, quando meu pai e minha mãe ali dormiam - com a porta aberta para melhor velar a prole - e quando eu podia ver vagamente, no claráo da lamparina, a cama grande, protegida do mundo noturno dos pesadelos que atravessam o sono e são uma espécie de réplica sinistra às poluçôes.

Como o outro polo sagrado da casa - polo esquerdo, tendendo ao ilícito em relação ao quarto dos pais, que era o polo direito, o da autoridade estabelecida, santuário do relógio de pêndulo e dos retratos dos avós -, estava o 
banheiro, onde todas as noites um de meus irmãos e eu nos encerrávamos, por necessidade natural, mas também para contarmos um ao outro espécies de folhetins com personagens animais, que alternadamente inventávamos ${ }^{2}$. Era nesse lugar que nos sentíamos mais cúmplices, enquanto fomentávamos complôs e elaborávamos toda uma mitologia quase secreta, retomada a cada noite, às vezes passada a limpo em cadernos, alimento da porção mais propriamente imaginativa de nossas vidas. Animais soldados, jóqueis, aviadores civis ou militares, lançados em competições bélicas, esportivas ou em intrigas policiais. Tenebrosas maquinaçóes políticas com tentativas de golpe de Estado, assassinatos, sequestros. Projetos de constituição que deveriam garantir o governo ideal. Intrigas sentimentais de uma pobreza absoluta e que se resumiam, na maior parte das vezes, a um casamento feliz, seguido do nascimento de muitos filhos, mas sem que se excluísse necessariamente o episódio final da viuvez. Invenção de máquinas de guerra, de corredores subterrâneos, de armadilhas e ciladas (às vezes consistindo apenas num simples fosso camuflado por folhagens, com paredes cobertas de lâminas cortantes e um fundo forrado de paus pontudos, para cortar em pedaços e perfurar quem ali caísse). Muitos combates e lutas ferozes (nos campos de batalha ou nos hipódromos). Após cada batalha, estatísticas detalhadas, com o número exato de prisioneiros, de feridos e de mortos para cada um dos adversários, que eram, por exemplo, os Gatos e os Cães, monarquistas os primeiros, e republicanos os segundos. Tudo isso, devidamente registrado em nossos cadernos em forma de narrativas, quadros, planos, croquis, com tabelas sintéticas e árvores genealógicas.

Além da série de lendas que inventávamos e do nosso panteão de heróis, o que talvez fosse mais claramente marcado pelo sagrado, nesses longos períodos passados no banheiro, era a própria clandestinidade de

2 N. do T.: A respeito dessa caracterização do sagrado em dois polos, direito e esquerdo, remetemos o leitor ao comentário de $\mathrm{D}$. Hollier na edição que serviu de base para a tradução (HOLLIER, 1979, p. 62-63). Hollier tece outras observaçóes ao longo do texto, que fazem referência sobretudo aos escritos autobiográficos de Leiris. 
nossas reuniôes. É claro que o resto da família sabia que estávamos lá, mas, por trás da porta fechada, eles não sabiam o que falávamos. Havia, naquilo que fazíamos, algo de mais ou menos proibido, o que, aliás, rendia reprimendas quando ficávamos muito tempo encerrados. Como numa "casa dos homens" de uma ilha qualquer da Oceania - onde os iniciados se reúnem e onde, de boca a boca e de geraçáo em geração se transmitem os segredos e os mitos, nesse cômodo que era nosso clube, arquitetávamos sem cessar nossa mitologia e procurávamos incansavelmente respostas para os vários enigmas que nos obcecavam no plano sexual. Meu irmão, sentado no grande trono, como um iniciado de grau superior; eu, o mais moço, sobre um reles urinol, que fazia as vezes de um tamborete de neófito. A descarga d'água e o buraco por si sós já eram coisas misteriosas e efetivamente perigosas (pois não me aconteceu um dia, brincando de correr em torno do orifício, imitando um cavalo de circo, de enfiar nele o pé, e meus pais, alertados em seguida, teremcustado para o soltar?); mais velhos e mais eruditos, não teríamos hesitado, sem dúvida, em ver neles uma comunicação direta com as divindades ctonianas.

Em relação à sala de estar - Olimpo que ficava fechado para nós nos dias de recepçáo -, o banheiro fazia papel de caverna, antro onde íamos nos inspirar, colocando-nos em contato com as forças mais obscuras e mais subterrâneas. Perante o sagrado direito da majestade parental, era lá que tomava corpo a magia suspeita de um sagrado esquerdo; era lá também que nos sentíamos mais à margem e mais separados frente a todos os outros, embora dentro do embriāo da sociedade secreta que formávamos, os dois irmãos, nos sentíssemos ainda mais íntimos e afinados um com o outro. Em suma, tratava-se, para nós, dessa coisa eminentemente sagrada que são todos os tipos de pacto - tal como o laço de cumplicidade que une os alunos de uma mesma classe contra os professores, laço suficientemente forte e sólido para que, dentre todos os imperativos morais que comandam as consciências adultas, bem poucos possam ser comparados àquele pelo qual as crianças se proíbem de dedurar-se mutuamente. 
No que se refere aos locais ao ar livre, relembro dois que, com o distanciamento do tempo e com as noçóes que adquiri posteriormente, me parecem ter sido impregnados, para a criança piedosa que eu era, de um caráter sagrado: uma espécie de deserto, de no man's land, que se estendia entre a zona de fortificaçóes e a pista de corridas de Auteuil, assim como o próprio hipódromo ${ }^{3}$.

Quando nossa mãe ou nossa irmã mais velha nos levava a passear no Bois de Boulogne ou no jardim público junto às estufas da cidade de Paris, acontecia muitas vezes de atravessarmos esse espaço mal qualificado (oposto ao mundo burguês das residências do mesmo modo que a aldeia, para aqueles que pertencem às sociedades ditas "selvagens", se opóe à selva, isto é, o mundo vago e apropriado para acontecerem todas as aventuras míticas e os estranhos encontros e que começa logo que se deixa o mundo devidamente demarcado da aldeia), essa "zona" verdadeiramente assombrada pelos marginais. Alertavam-nos, se ocorresse de pararmos para brincar nesse lugar, contra os desconhecidos (na verdade, dou-me conta disso hoje em dia, eram os sátiros) que poderiam, sob pretextos falaciosos, tentar nos arrastar para o matagal. Ambiente marginal, excepcionalmente marcado por um tabu, pelo sobrenatural e pelo sagrado, tão diferente dos jardins públicos, onde tudo era previsto, organizado, aparado, e onde as placas de proibido pisar na grama, ainda que fossem sinais de tabu, não podiam indicar mais que um sagrado bem esmaecido!

Outro lugar a céu aberto que nos fascinava, a mim e a um de meus irmãos, era a pista de corridas de Auteuil. De uma via para cavalos que contornava parcialmente a pista, podíamos, ele e eu, olhar os jóqueis - de jaquetas multicoloridas em seus cavalos de pelo lustroso - transporem uma sebe, subir num pequeno morro coberto de grama e desaparecer atrás dele.

3 N. do T.: Essa zona era um conjunto de terrenos baldios que se constituiu em torno de Paris perto das antigas fortificaçóes - muro criado entre 1841 e 1844 para demarcar os limites da cidade - e que abrigava, no início do século XX, uma população muito pobre (Disponível em: <https://fr.wikipedia.org/wiki/La_Zone_(Paris)>. Acesso em: 12 de abril de 2016). 
Sabíamos que era lá que as pessoas (aquelas que avistávamos amontoadas nas arquibancadas e cujo clamor ouvíamos na hora da chegada) apostavam e se arruinavam por esses cavaleiros de paramentos reluzentes, como um colega de meu pai que, depois de ter possuído "cavalos e carro", havia perdido toda sua fortuna no jogo, e a quem meu pai, mais tarde, seguidamente emprestava algum dinheiro quando o encontrava na Bolsa. Lugar sobretudo prestigioso, em razão do espetáculo que ali se desenrolava e das somas consideráveis que eram ganhas ou perdidas; lugar entre todos imoral, na medida em que tudo lá se mede em função de sorte e azar, e contra o qual meu pai se enfurecia, preocupado com a ideia de que, mais velhos, pudéssemos nos tornar jogadores.

Uma de nossas maiores alegrias era quando a largada de uma corrida se dava perto do lugar onde estávamos. O starter, de sobrecasaca, em seu cavalo de músculos de lutador, troncudo, ao lado dos puros-sangues que participavam da prova; com movimentos saltitantes de galos e ondulações de cisnes, o grupo de competidores se reunindo para a largada; depois, terminado o sempre trabalhoso alinhamento, o brusco galope do pelotão e o ruído dos cascos no solo, cujas mais íntimas vibraçóes podíamos sentir. Ainda que eu jamais tenha tido grande gosto pelos esportes, conservei dessa época uma impressão de deslumbramento que me faz olhar todo espetáculo esportivo como uma espécie de parada ritual. Apetrechos de montaria dos jóqueis, cordas brancas dos ringues de boxe e todos os preparativos: o desfile dos concorrentes, a apresentação dos adversários, o ofício do starter ou do árbitro; tudo o que se pode perceber, também nos bastidores, em matéria de fomentações, massagens, dopings, dietas especiais, regulamentos minuciosos. Poderíamos dizer que os protagonistas agem num mundo à parte, ao mesmo tempo mais próximos e mais isolados do público do que estão, por exemplo, os artistas num palco. Porque aqui nada é falso: apesar da importância da encenação, o espetáculo esportivo, de desenlace teoricamente imprevisível, é um ato real e não uma simulação em que todas as peripécias se desenrolam de acordo com o que foi acertado previamente. Por isso, uma participação infinitamente maior, ao mesmo tempo que uma consciência muito mais 
intensa da separação, já que os seres de que ficamos aqui separados não são manequins convencionais - vagos reflexos de nós mesmos, sem nada, no fundo, de comum conosco - mas seres como nós, de uma densidade ao menos igual, e que poderiam ser nós mesmos.

Durante todo esse período de paixão pelas corridas, meu irmão e eu imaginávamos muitas vezes que, quando fôssemos mais velhos, nos tornaríamos jóqueis - como tantos meninos dos bairros pobres sonham tornar-se ciclistas de competição ou boxeadores. Tal como o profeta, o grande revolucionário ou o grande conquistador, era como se o campeão tivesse um destino traçado, e a ascensão vertiginosa de quem muitas vezes saiu das camadas mais desfavorecidas da população seria um sinal de sorte ou de força mágica - de um mana - excepcional que lhe permitiria subir de uma vez todos os degraus e alcançar um estrato social um pouco marginal, é verdade, mas desproporcional em relação a tudo o que um homem comum pode razoavelmente esperar, seja qual for seu berço. Em alguns aspectos, ele lembra o xamã, que muitas vezes, por sua origem, não passa de um deserdado, mas vence o destino com uma revanche espetacular, pelo fato de que ele e apenas ele, excluídos os outros, tem ligação com os espíritos.

Sem dúvida, meu irmão e eu deduzíamos tudo isso de maneira confusa, quando nos imaginávamos paramentados de jaquetas como se fossem brasóes ou vestimentas litúrgicas que nos distinguiriam dos outros e ao mesmo tempo nos uniriam a eles enquanto alvos, suportes da efervescência coletiva, pontos de convergência e receptáculos dos olhares deles, fixados em nós como se por meio de tachinhas eles pudessem pregar em nós seu prestígio. Mais do que a cartola, o revólver de tambor e a niqueleira do pai, aquelas finas túnicas de seda teriam afirmado nossa força, nosso mana particular de pessoas que vencem todos os obstáculos sobre um cavalo e se expóem vitoriosamente a todos os riscos da queda.

Ao lado dos objetos, dos lugares, dos espetáculos que exerciam sobre nós uma atração tão especial (a atração de tudo o que se mostra separado do mundo comum, como, por exemplo, o bordel - cheio de nudezes e de uma atmosfera de sauna - tão distante do mundo vestido e arejado da rua, ainda 
que a separaçáo se faça por uma simples soleira, sinal concreto do tabu que pesa sobre o lugar de perdiçáo), encontro circunstâncias, fatos, por assim dizer imponderáveis, que me dáo a percepçáo aguda da existência de um reino diferente, reservado, sem nenhum paralelo com o resto, e destacado da massa do profano com a mesma crueza deslumbrante e insólita que, nos cabarés noturnos de apresentação de mulheres, os corpos depilados e empoados têm quando irrompem passando a dois dedos das mesas cercadas por clientes apáticos e suados. Quero falar de expressóes de linguagem, de palavras por si só ricas de significados, ou de palavras mal-entendidas ou mal lidas, que desencadeiam bruscamente uma espécie de vertigem no momento em que percebemos que não são o que até entáo acreditávamos que eram. Tais palavras frequentemente desempenharam, na minha infância, a funçáo de chaves, seja porque, por sua própria sonoridade, carregassem surpreendentes perspectivas, seja porque, ao descobrir que anteriormente eram desmembradas, apreendê-las de repente em sua integridade desempenhou, em alguma medida, o papel de revelaçáo, como um véu que se rasga de repente ou uma verdade que se manifesta bruscamente.

Algumas dessas palavras ou expressōes estavam ligadas a lugares, circunstâncias e imagens que explicam, por sua própria natureza, a força emotiva de que essas palavras ou expressōes eram carregadas. Por exemplo, a "Casa Vazia", nome que meus irmãos e eu tínhamos dado a um conjunto de rochedos, agrupados numa espécie de dólmen natural nas redondezas de Nemours, não muito distante da casa onde nossos pais, por muitos anos seguidos, nos levaram para passar as férias de verão. A "casa vazia": isso soa como soavam nossas vozes sob o arco de granito; evoca a ideia do domicílio deserto de um gigante, de um templo de proporçóes imponentes esculpido numa pedra prodigiosamente ancestral.

Também pertence ao domínio estrito do sagrado um nome próprio, Rebeca, aprendido na História Sagrada que evoca em mim uma imagem tipicamente bíblica: uma mulher de braços e rosto acobreados, vestindo uma longa túnica e um amplo véu na cabeça, com um cântaro no ombro e o braço apoiado na borda de um poço. Nesse caso, o próprio nome funcionava 
de uma maneira precisa, fazendo pensar, de um lado, em alguma coisa doce e aromática, como passas de uva ou uvas moscatel; e, de outro, em algo de duro e obstinado, por causa do $\mathrm{R}$ inicial e principalmente pelo ...ca, que atualmente encontro em palavras como "Meca" ou "impecável".

Por último, um outro vocábulo foi para mim, pelo menos durante algum tempo, dotado do valor mágico de uma senha ou de um "abracadabra": a exclamação "Baoukta", inventada por meu irmão mais velho como grito de guerra quando brincávamos de peles-vermelhas e ele personificava o grande chefe corajoso e temido. O que me espantava nisso, como no nome Rebeca, era principalmente o ar esquisito do termo, a estranheza que ele carregava, como uma palavra que tivesse pertencido à língua dos marcianos ou dos demônios, ou ainda que tivesse sido extraída de um vocabulário especial, carregado de um significado oculto, cujo segredo meu irmão mais velho, o principal oficiante, seria o único a conhecer.

Além dessas palavras que - se é possível dizer - falavam por si mesmas, outros fatos de linguagem me trouxeram a vaga percepçáo dessa espécie de desvio ou descompasso que caracteriza para mim a passagem de um estado comum a um estado privilegiado, mais cristalino, mais singular, o deslizamento de um estado profano para um estado sagrado. Trata-se, na verdade, de ínfimas descobertas: correçôes de audição ou de leitura que, em presença de duas variantes de uma mesma palavra, fazem nascer da divergência entre elas um problema particular. Diríamos que a linguagem nesse caso estaria como que torcida e que na mínima distância que separa os dois vocábulos - tornados ambos plenos de estranheza quando, agora, eu os comparo um ao outro (como se cada um deles fosse justamente o outro, esfolado e torcido) - abria-se uma brecha capaz de deixar passar um mundo de revelaçóes.

Lembro que um dia, brincando com soldados de chumbo, deixei cair um deles, apanhei-o e, vendo que não estava quebrado, gritei “...inda bem!”. Em seguida, alguém que estava por ali - mãe, irmã ou irmão 
mais velho - me fez reparar que não se diz "inda bem", mas "ainda bem", ${ }^{4}$ o que teve o efeito de uma descoberta chocante. Foi a mesma coisa quando descobri que o nome de Moïse [Moisés] não se pronuncia "Moisse" [morsa], como eu acreditava quando, lendo muito mal ainda, estudava a História Sagrada, e essas duas palavras ganharam uma sonoridade particularmente perturbadora para mim: "Moïse", "Moisse”, a própria imagem de seu berço, possivelmente por causa da palavra "osier" [vime] ou simplesmente porque já tinha ouvido, embora sem prestar atenção, chamarem alguns berços de "Moïse" [moisés]. Mais tarde, ao estudar os nomes dos departamentos da França, nunca mais fui insensível ao nome Seine-et-Oise, porque esse antigo erro de leitura cometido em relação a um nome bíblico tinha atribuído para sempre, no meu espírito, um certo valor singular a todas as palavras mais ou menos parecidas com "Moïse" ou "Moisse". 5

De uma maneira análoga àquela em que, para mim, se opunham a expressão “...inda bem” e sua forma retificada “ainda bem”, nós distinguíamos, meus irmãos e eu, quando íamos para o campo nas férias com nossos pais, o areião e o areal, dois lugares arenosos que só se diferenciavam entre si pelas dimensóes bem maiores do segundo ${ }^{6}$. Mais tarde, experimentávamos um prazer comparável ao que apenas as discussóes ditas "bizantinas" podem proporcionar, ao batizar dois tipos diferentes de avióes de papel que confeccionávamos, um, o tipo retilíneo, e outro, o curvilíneo. Assim agindo, fazíamos como os ritualistas, para quem o sagrado se resume afinal a um sistema sutil de distinção, de filigranas e de detalhes de etiqueta.

Se comparo os diversos fatos - o chapéu de copa alta, como sinal da autoridade do pai; o revólver Smith e Wesson, como sinal de sua coragem e força; a niqueleira, sinal de sua riqueza enquanto sustentáculo financeiro

4 N. do T.: Os termos usados originalmente por Leiris são "...reusement" e "heureusement".

5 N. do T.: as palavras que se referem a Moisés, ao departamento de Seine-et-Oise e ao vime [osier], bem como moisse [morsa], são expressas em sons que guardam certa semelhança fonética entre si.

6 N. do T.: Os termos usados originalmente por Leiris são "sablonnière" e "sablière". 
da casa; a salamandra, que podia nos queimar, mesmo sendo, em princípio, o gênio protetor do lar; o quarto parental, resumo da noite; o banheiro, em cujo recôndito compartilhávamos relatos mitológicos e hipóteses sobre a natureza das coisas sexuais; a zona perigosa que se estendia para além das fortificaçóes; o hipódromo, onde se apostam grandes somas na sorte ou na habilidade de personagens de roupas e de gestos prestigiosos; as janelas abertas, por alguns elementos da linguagem, para um mundo onde perdemos o pé -, se reúno todos esses fatos emprestados do que foi minha existência cotidiana quando eu era criança, vejo formar-se pouco a pouco uma imagem do que é para mim o sagrado.

Algo de prestigioso, como os atributos paternos ou a grande casa dos rochedos. Algo de insólito, como os paramentos dos jóqueis ou certas palavras de ressonância exótica. Algo de perigoso, como os carvôes incandescentes ou o matagal repleto de marginais. Algo de ambíguo, como os acessos de tosse que dilaceram, mas transformam alguém em herói de tragédia. Algo de proibido, como a sala de estar onde os adultos realizam seus ritos. Algo de secreto, como as confabulaçóes em meio ao mau cheiro dos sanitários. Algo de vertiginoso, como o salto dos cavalos a galope ou as caixas de múltiplos compartimentos da língua. Algo que, em suma, não consigo conceber de outra forma senão marcada, de uma maneira ou de outra, pelo sobrenatural.

Mesmo que um dos objetivos mais "sagrados" a que um homem possa se propor seja o de adquirir um conhecimento de si tão preciso e intenso quanto possível, revela-se desejável que cada um, perscrutando suas lembranças com o máximo de honestidade, examine se não pode descobrir algum indício que lhe permita discernir nisso que cor tem para si mesmo a própria noção de sagrado. 
